\title{
Mathematical Model of MMT with Profit Return under Monopolistic Competition
}

\author{
Yasuhito Tanaka \\ Faculty of Economics, Doshisha University \\ Kamigyo-ku, Kyoto, 602-8580, Japan \\ Tel: $81-75-251-3648$ \\ E-mail: yatanaka@mail.doshisha.ac.jp
}

Received: October 18, 2021 Accepted: November 1, $2021 \quad$ Published: November 2, 2021

doi: $10.5296 /$ jsss.v8i2.19073

URL: https://doi.org/10.5296/jsss.v8i2.19073

\begin{abstract}
Even under constant returns to scale technology there is a positive profit return if the goods are produced in monopolistic competition. By a two-periods overlapping generations (OLG) model with production in monopolistic competition under constant returns to scale in which the economy grows by technological progress and the older generation consumers receive the profits, we consider the problem of budget deficit. We show that the budget deficit equals the difference between the net savings of the younger generation consumers excluding the profits received in the future and that of the older generation consumers in each of the following cases. Also, the following results will be proved. 1) A budget deficit is necessary to realize full employment with constant price when the economy grows. 2) If the budget deficit exceeds the level necessary and sufficient to maintain full employment in a growing economy with constant price, inflation will occur. A stable budget deficit is necessary to prevent further inflation. 3) If the budget deficit is insufficient to maintain full employment, a recession with involuntary unemployment occurs. We can overcome a recession and restore full employment making a budget deficit larger than the one necessary and sufficient to maintain full employment without a recession. Since we can maintain full employment by constant budget deficits, we should not offset the deficit created for overcoming the recession by budget surpluses.
\end{abstract}

Keywords: MMT, economic growth, budget deficit, monopolistic competition, profit return JEL Classification: E12, E24 


\section{Introduction}

In previous studies we examined the arguments for fiscal policy by Lerner's $(1943,1944)$ Functional Finance Theory and MMT (Modern Monetary Theory, Wray (2015), Mitchell, Wray and Watts (2019), Kelton (2020) $)^{1}$ by a static model or an overlapping generations model of perfect competition with constant returns to scale technology. Under perfect competition with constant returns to scale there is no corporate profit. In order to include the existence of corporate profits in the analysis, it is possible to consider the case of production using not only labor but also capital, but this paper deals with a simpler model of monopolistic competition with constant returns to scale in which labor is the only production factor. Maintaining the basics of the neoclassical microeconomic framework, such as consumers' utility maximization under budget constraints, and equilibrium of supply and demand of goods in monopolistic competition with constant returns to scale technology, the idea of the effect of fiscal policy in Functional Finance Theory and MMT is discussed by a simple mathematical model.

Using a two-periods (two-generations) overlapping generations model with production in monopolistic competition under constant returns to scale technology in which the economy grows by technological progress and the older generation consumers receive the corporate profits, the following results will be proved.

1) A budget deficit is necessary to achieve full employment under constant price when the economy grows by technological progress. (Section 3)

2) If the budget deficit exceeds the level necessary and sufficient to maintain full employment in a growing economy under constant price, inflation will occur. A stable budget deficit is necessary to prevent further inflation. (Section 4)

3) If the budget deficit is insufficient to maintain full employment, a recession with involuntary unemployment will occur. (Section 5)

We can overcome a recession and restore full employment making a budget deficit larger than the one necessary and sufficient to maintain full employment without a recession.

Since we can maintain full employment through constant budget deficits, we should not offset the deficit created for overcoming recession by budget surpluses.

We consider restoration of full employment by fiscal spending (Section 6) and tax reduction (Sections 7).

Also, we show that the budget deficit equals the difference between the net savings of the younger generation consumers and that of the older generation consumers in each case. In the overlapping generations model the net savings means the consumptions of consumers in their older period (the second period) net of the profit returns which are received in their older

${ }^{1}$ Other references are Mochizuki (2020), Morinaga (2020) and Park (2020). These are introductory texts of MMT written in Japanese. 
period. Under full employment we can define the budget deficit which is necessary and sufficient to realize full employment. If full employment is not realized, the independent variable is the budget deficit, and the national income and the savings are determined by the budget deficit not that the savings of consumers determine the budget deficit.

We think that the essence of MMT with respect to fiscal policy lies in the following two points.

1. "Financial resources is not necessary for fiscal spending" or "Taxes are not a source of revenue for fiscal spending"

From a macroeconomic perspective, fiscal spending has a role to increase the demand for goods, while taxes have a role to reduce demand by reducing disposable income of consumers. To achieve full employment and stable growth without inflation, an adequate balance between the size of fiscal spending and taxes is necessary, not those taxes are necessary for fiscal spending.

2. There is no need to pay off government debt with taxes.

Although not discussed specifically in this paper, all government bonds could be redeemed tomorrow without raising taxes if it wanted to (although it does not have to). The central bank could just buy them all up. This may have the effect of lowering interest rates, but it will not directly increase demand for goods and will not cause high-rate inflation because people's assets will not increase (unless the central bank buys them at prices above face value) and it will not generate income. If it is done during a recession, even low-rate inflation will not occur. Since government bonds are also money in the same broad sense as bank time deposits ("liquidity in the broad sense"), and the central bank's purchase of government bonds does not increase the money supply in that sense, inflation does not occur from the perspective of the Quantity Theory of Money.

In the next section we consider behavior of consumers and firms. In Appendix we will show that if the profit returns are received by the younger generation consumers, the budget deficit equals the difference between the savings of the younger generation consumers and that of the older generation consumers.

\section{Behavior of Consumers and Firms}

We use a two-periods (generations) overlapping generations (OLG) model according to the model used by Otaki (2007, 2009, 2015). Consumers live over two-periods, the younger period (the first period) and the older period (the second period). They work only in the younger period. They consume goods in their older period by their savings carried over from their younger period and the profit returns received from firms. There is a continuum of goods indexed by $z \in[0,1]$. Each good is monopolistically produced by Firm $z$ with only labor as a production factor under constant returns to scale technology. The number (or the size) of the firms is normalized to one. Let $c^{i}(z)$ be the consumption of good $\mathrm{z}$ in Period $i, \quad i=1,2$ of a consumer, $p^{i}(z)$ be the price of $\operatorname{good} z$ in Period $i, \quad i=1,2$. Period 1 is the younger period, and Period 2 is the older period for consumers. Consumers choose their 
consumptions over two periods to maximize their utility subject to the budget constraint. Let $L$ be the employment and $L_{f}$ be the labor supply or the employment in the full employment state.

Let

$$
C_{1}=\left(\int_{0}^{1} c_{1}(z)^{1-\frac{1}{\eta}} d z\right)^{\frac{1}{1-\frac{1}{\eta}}}, \quad C_{2}=\left(\int_{0}^{1} c_{2}(z)^{1-\frac{1}{\eta}} d z\right)^{\frac{1}{1-\frac{1}{\eta}}}
$$

be the consumption basket in Periods 1 and 2 of a consumer and

$$
P_{1}=\left(\int_{0}^{1} p_{1}(z)^{1-\eta} d z\right)^{\frac{1}{1-\eta}}, P_{2}=\left(\int_{0}^{1} p_{2}(z)^{1-\eta} d z\right)^{\frac{1}{1-\eta}}
$$

be the price index in each period. $\eta$ is the inverse of the degree of differentiation of the goods. $\eta>1$ and in the limit when $\eta \rightarrow \infty$, the goods are homogeneous. The utility of consumption is represented by

$$
C_{1}^{\alpha} C_{2}^{1-\alpha}
$$

$0<\alpha<1$. It is the propensity to consume. Denote the disposable income over two periods of an employed or an unemployed consumer by $D I$. The budget constraint for a consumer is

$$
\int_{0}^{1} p_{1}(z) c_{1}(z) d z+\int_{0}^{1} p_{2}(z) c_{2}(z) d z=D I
$$

The Lagrange function is

$$
\mathcal{L}=C_{1}^{\alpha} C_{2}^{1-\alpha}-\lambda\left(\int_{0}^{1} p_{1}(z) c_{1}(z) d z+\int_{0}^{1} p_{1}(z) c_{1}(z) d z-D I\right) .
$$

The first order conditions for maximization of $\mathcal{L}$ are

$$
\begin{gathered}
\alpha C_{1}^{\alpha-1} C_{2}^{1-\alpha}\left(\int_{0}^{1} c_{1}(z)^{1-\frac{1}{\eta}} d z\right)^{\frac{1}{1-\frac{1}{\eta}}-1} c_{1}(z)^{-\frac{1}{\eta}}-\lambda p_{1}(z)=0, \\
(1-\alpha) C_{1}^{\alpha} C_{2}^{-\alpha}\left(\int_{0}^{1} c_{2}(z)^{1-\frac{1}{\eta}} d z\right)^{\frac{1}{1-\frac{1}{\eta}}-1} c_{2}(z)^{-\frac{1}{\eta}}-\lambda p_{2}(z)=0 .
\end{gathered}
$$

From them 


$$
\begin{gathered}
\alpha C_{1}^{\alpha-1} C_{2}^{1-\alpha}\left(\int_{0}^{1} c_{1}(z)^{1-\frac{1}{\eta}} d z\right)^{\frac{1}{1-\frac{1}{\eta}}-1} c_{1}(z)^{1-\frac{1}{\eta}}-\lambda p_{1}(z) c_{1}(z)=0, \\
(1-\alpha) C_{1}^{\alpha} C_{2}^{-\alpha}\left(\int_{0}^{1} c_{2}(z)^{1-\frac{1}{\eta}} d z\right)^{\frac{1}{1-\frac{1}{\eta}}-1} c_{2}(z)^{1-\frac{1}{\eta}}-\lambda p_{2}(z) c_{2}(z)=0 .
\end{gathered}
$$

They mean

$$
\begin{gathered}
\alpha C_{1}^{\alpha} C_{2}^{1-\alpha}-\lambda \int_{0}^{1} p_{1}(z) c_{1}(z) d z=0, \\
(1-\alpha) C_{1}^{\alpha} C_{2}^{1-\alpha}-\lambda \int_{0}^{1} p_{2}(z) c_{2}(z) d z=0 .
\end{gathered}
$$

Therefore, we have

$$
\int_{0}^{1} p_{1}(z) c_{1}(z) d z=\frac{\alpha}{1-\alpha} \int_{0}^{1} p_{2}(z) c_{2}(z) d z,
$$

and

$$
\begin{gathered}
\int_{0}^{1} p_{1}(z) c_{1}(z) d z=\alpha D I \\
\int_{0}^{1} p_{2}(z) c_{2}(z) d z=(1-\alpha) D I
\end{gathered}
$$

From (1) and (2)

$$
\begin{gathered}
\alpha^{1-\eta}\left(C_{1}^{\alpha-1} C_{2}^{1-\alpha}\right)^{1-\eta}\left(\int_{0}^{1} c_{1}(z)^{1-\frac{1}{\eta}} d z\right)^{-1} c_{1}(z)^{1-\frac{1}{\eta}}-\lambda^{1-\eta} p_{1}(z)^{1-\eta}=0, \\
(1-\alpha)^{1-\eta}\left(C_{1}^{\alpha} C_{2}^{-\alpha}\right)^{1-\eta}\left(\int_{0}^{1} c_{2}(z)^{1-\frac{1}{\eta}} d z\right)^{-1} c_{2}(z)^{1-\frac{1}{\eta}}-\lambda^{1-\eta} p_{2}(z)^{1-\eta}=0 .
\end{gathered}
$$

Then, 


$$
\begin{array}{r}
\alpha^{1-\eta}\left(C_{1}^{\alpha-1} C_{2}^{1-\alpha}\right)^{1-\eta}\left(\int_{0}^{1} c_{1}(z)^{1-\frac{1}{\eta}} d z\right)^{-1} \int_{0}^{1} c_{1}(z)^{1-\frac{1}{\eta}} d z-\lambda^{1-\eta} \int_{0}^{1} p_{1}(z)^{1-\eta} d z=0, \\
(1-\alpha)^{1-\eta}\left(C_{1}^{\alpha} C_{2}^{-\alpha}\right)^{1-\eta}\left(\int_{0}^{1} c_{2}(z)^{1-\frac{1}{\eta}} d z\right)^{-1} \int_{0}^{1} c_{2}(z)^{1-\frac{1}{\eta}} d z-\lambda^{1-\eta} \int_{0}^{1} p_{2}(z)^{1-\eta} d z=0 .
\end{array}
$$

They mean

$$
\begin{aligned}
& \alpha C_{1}^{\alpha-1} C_{2}^{1-\alpha}-\lambda\left(\int_{0}^{1} p_{1}(z)^{1-\eta} d z\right)^{\frac{1}{1-\eta}}=0, \\
& (1-\alpha) C_{1}^{\alpha} C_{2}^{-\alpha}-\lambda\left(\int_{0}^{1} p_{2}(z)^{1-\eta} d z\right)^{\frac{1}{1-\eta}}=0 .
\end{aligned}
$$

Therefore, we get

$$
\alpha C_{1}^{\alpha} C_{2}^{1-\alpha}-\lambda P_{1} C_{1}=0,(1-\alpha) C_{1}^{\alpha} C_{2}^{1-\alpha}-\lambda P_{2} C_{2}=0 .
$$

By (3) and (4)

$$
P_{1} C_{1}=\frac{\alpha}{\lambda} C_{1}^{\alpha} C_{2}^{1-\alpha}=\alpha D I, P_{2} C_{2}=\frac{1-\alpha}{\lambda} C_{1}^{\alpha} C_{2}^{1-\alpha}=(1-\alpha) D I .
$$

From them and (1)

$$
P_{1} C_{1}\left(\int_{0}^{1} c_{1}(z)^{1-\frac{1}{\eta}} d z\right)^{-1} c_{1}(z)^{-\frac{1}{\eta}}=P_{1} C_{1}^{\frac{1}{\eta}} C_{1}(z)^{-\frac{1}{\eta}}=\left(P_{1} C_{1}\right)^{\frac{1}{\eta}} C_{1}(z)^{-\frac{1}{\eta}} P_{1}^{1-\frac{1}{\eta}}=p_{1}(z) .
$$

This means

$$
c_{1}(z)=\frac{\alpha D I}{P_{1}}\left(\frac{P_{1}}{p_{1}(z)}\right)^{\eta} .
$$

This is the demand function for good $z$ of a consumer in his younger period. The demand of an older generation consumer in the same period is 


$$
c_{2}(z)=\frac{(1-\alpha) D I^{o}}{P_{1}}\left(\frac{P_{1}}{p_{1}(z)}\right)^{\eta}
$$

$D I^{O}$ is the disposable income of an older generation consumer. The total disposable income is written as

$$
\left[\alpha D I+(1-\alpha) D I^{o}\right] L_{f}
$$

Then, $D I$ and $D I^{o}$ mean the average income of the employed and unemployed younger generation consumers and that of the older generation consumers who are employed or unemployed in their younger period.

Now let us consider profit maximization of a firm in Period 1. The profit of the firm producing good $z$ is

$$
\pi(z)=\left(p_{1}(z)-\frac{w}{y}\right) \frac{\alpha D I+(1-\alpha) D I^{o}}{P_{1}} L_{f}\left(\frac{P_{1}}{p_{1}(z)}\right)^{\eta}
$$

$w$ is the nominal wage rate and $y$ is the labor productivity. The condition for profit maximization with respect to $p_{1}(z)$ given $P_{1}$ is

$$
\frac{\partial \pi(z)}{\partial p_{1}(z)}=\left[\alpha D I+(1-\alpha) D I^{o}\right] L_{f} P_{1}^{\eta-1}\left[(1-\eta) p_{1}(z)^{-\eta}+\eta \frac{w}{y} p_{1}(z)^{-\eta-1}\right]=0 .
$$

From this

$$
p_{1}(z)=-\frac{\eta}{1-\eta} \frac{w}{y}=\frac{1}{1-\frac{1}{\eta}} \frac{w}{y}
$$

All firms have the same cost function. In the equilibrium the prices of all goods are equal. Then,

$$
P_{1}=p_{1}(z)=\frac{1}{1-\frac{1}{\eta}} \frac{w}{y}
$$

and

$$
c_{1}(z)=\frac{\alpha D I}{P_{1}}, c_{2}(z)=\frac{(1-\alpha) D I^{o}}{P_{1}}
$$

in the equilibrium. Hereafter we call $P_{1}$ and $P_{2}$ the prices in Periods 1 and 2 . 
The government determines the demand for good $z, g(z)$, given its expenditure $G$ to maximize

$$
\mathcal{G}=\left(\int_{0}^{1} g(z)^{1-\frac{1}{\eta}} d z\right)^{\frac{1}{1-\frac{1}{\eta}}}
$$

subject to

$$
\int_{0}^{1} p_{1}(z) g(z) d z=G
$$

The condition for maximization of $\mathcal{G}$ is

$$
\left(\int_{0}^{1} g(z)^{1-\frac{1}{\eta}} d z\right)^{\frac{1}{1-\frac{1}{\eta}}-1} g(z)^{-\frac{1}{\eta}}-\lambda_{g} p_{1}(z)=0
$$

$\lambda_{g}$ is the Lagrange multiplier. This means

$$
\begin{gathered}
\left(\int_{0}^{1} g(z)^{1-\frac{1}{\eta}} d z\right)^{-1} \int_{0}^{1} g(z)^{1-\frac{1}{\eta}} d z-\lambda_{g}^{1-\eta} \int_{0}^{1} p_{1}(z)^{1-\eta} d z=0, \\
\left(\int_{0}^{1} g(z)^{1-\frac{1}{\eta}} d z\right)^{\frac{1}{1-\frac{1}{\eta}}-1} \int_{0}^{1} g(z)^{1-\frac{1}{\eta}} d z-\lambda_{g} \int_{0}^{1} p_{1}(z) g(z) d z=0 .
\end{gathered}
$$

Thus,

$$
\begin{gathered}
\left(\int_{0}^{1} p_{1}(z)^{1-\eta} d z\right)^{\frac{1}{1-\eta}}=P_{1}=\frac{1}{\lambda_{g}}, \\
\mathcal{G}=\lambda G=\frac{G}{P_{1}} .
\end{gathered}
$$

Again from (5)

$$
\mathcal{G}^{\frac{1}{\eta}} g(z)^{-\frac{1}{\eta}}=\left(\frac{G}{P_{1}}\right)^{\frac{1}{\eta}} g(z)^{-\frac{1}{\eta}}=\frac{p_{1}(z)}{P_{1}} .
$$

This means

$$
g(z)=\frac{G}{P_{1}}\left(\frac{P_{1}}{p_{1}(z)}\right)^{\eta}
$$




\section{Il Macrothink}

This is the demand for good $z$ of the government. In the equilibrium

$$
g(z)=\frac{G}{P_{1}}
$$

The total demand for the goods is

$$
\frac{\alpha D I+(1-\alpha) D I^{o}+G}{P_{1}} L_{f} .
$$

In the equilibrium the total demand equals the total supply which is $y L . L$ is the employment. Under full employment $L=L_{f}$.

The economy grows by technological progress. The labor productivity increases at the rate $\gamma-1>0$ from period to period. The nominal wage rate $w$ also increases at the rate $\gamma-1$ under constant price. In a period, Period 1 , it is $y$. If $w=y$,

$$
P_{1}=\frac{1}{1-\frac{1}{\eta}}
$$

Let $\Pi_{1}$ be the profit return of a firm for a consumer in Period 1. Then,

$$
\Pi_{1}=\left(\frac{1}{1-\frac{1}{\eta}}-1\right) w \frac{L}{L_{f}}=\left(\frac{1}{\eta-1}\right) w \frac{L}{L_{f}}>0
$$

For simplicity we assume that every older generation consumer receives the profit return including consumers who were unemployed in their younger period. Of course, we can assume that only the older generation consumers who were employed receive the profit returns. Essentially, the result is the same. In the next period (Period 2) the labor productivity increases at the rate of $\gamma-1$. Thus, the profit return of a firm for a consumer in that period is

$$
\left(\frac{1}{\eta-1}\right) \gamma w \frac{L}{L_{f}}
$$

Note that $\gamma w$ is the nominal wage rate (without inflation) in Period 2. Denote the profit return which is received by an older generation consumer in Period 2 by $\Pi_{2}$. Then,

$$
\Pi_{2}=\left(\frac{1}{\eta-1}\right) \gamma w \frac{L}{L_{f}} .
$$




\section{MIN Macrothink}

\section{Economic Growth and Budget Deficit}

We suppose full employment in this section. Thus,

$$
\Pi_{2}=\left(\frac{1}{\eta-1}\right) \gamma w
$$

Let $G$ and $T$ be the government expenditure and the (total) tax in Period 1. The younger generation consumers pay the taxes. Suppose $w=y$. The disposable income of younger generation consumers in total is

$$
y L_{f}+\Pi_{2} L_{f}-T
$$

The (total) savings of the younger generation consumers in Period 1 is

$$
(1-\alpha)\left(y L_{f}+\Pi_{2} L_{f}-T\right)
$$

This is equal to the consumption of the older generation consumers in Period 2. Since they receive the profit returns in the next period, their net savings is

$$
(1-\alpha)\left(y L_{f}+\Pi_{2} L_{f}-T\right)-\Pi_{2} L_{f}=(1-\alpha)\left(y L_{f}-T\right)-\alpha \Pi_{2} L_{f}
$$

The government expenditure and the tax in Period 2 are $\gamma G$ and $\gamma T$. The consumption of the younger generation consumers in Period 2 is

$$
\alpha\left(\gamma y L_{f}+\Pi_{3} L_{f}-\gamma T\right)=\alpha \gamma\left(y L_{f}+\Pi_{2} L_{f}-T\right)
$$

$\Pi_{3}$ is the profit received by an older generation consumer in Period 3. Under full employment

$$
\Pi_{3}=\left(\frac{1}{\eta-1}\right) \gamma^{2} y=\gamma \Pi_{2}
$$

The net savings of the younger generation consumers is

$$
(1-\alpha) \gamma\left(y L_{f}+\Pi_{2} L_{f}-T\right)-\gamma \Pi_{2} L_{f}=(1-\alpha) \gamma\left(y L_{f}-T\right)-\gamma \alpha \Pi_{2} L_{f}
$$

Let $P_{2}$ be the price in Period 2. The nominal total supply in Period 2 is

$$
\gamma P_{2} y L_{f}
$$




\section{Macrothink}

The nominal total demand is

$$
\alpha \gamma\left(y L_{f}+\Pi_{2} L_{f}-T\right)+(1-\alpha)\left(y L_{f}+\Pi_{2} L_{f}-T\right)+\gamma G
$$

From the equilibrium between the total supply and the total demand, we get

$$
\gamma P_{2} y L_{f}=\alpha \gamma\left(y L_{f}+\Pi_{2} L_{f}-T\right)+(1-\alpha)\left(y L_{f}+\Pi_{2} L_{f}-T\right)+\gamma G
$$

From this

$$
\gamma y L_{f}=\alpha \gamma\left(y L_{f}+\Pi_{2} L_{f}-T\right)+(1-\alpha)\left(y L_{f}+\Pi_{2} L_{f}-T\right)+\gamma G-\gamma\left(P_{2}-1\right) y L_{f} .
$$

Since $P_{2}=\frac{1}{1-\frac{1}{\eta}}$ and $\Pi_{2}=\frac{1}{\eta-1} \gamma y$, we get

$$
\gamma y L_{f}=\alpha \gamma\left(y L_{f}+\Pi_{2} L_{f}-T\right)+(1-\alpha)\left(y L_{f}+\Pi_{2} L_{f}-T\right)+\gamma G-\Pi_{2} L_{f} .
$$

Then,

$$
\gamma(G-T)=\gamma(1-\alpha)\left(y L_{f}-T\right)-(1-\alpha)\left(y L_{f}-T\right)-(1-\alpha) \Pi_{2} L_{f}-\alpha \gamma \Pi_{2} L_{f}+\Pi_{2} L_{f}
$$

$$
=(\gamma-1)\left[(1-\alpha)\left(y L_{f}-T\right)-\alpha \Pi_{2} L_{f}\right]
$$

(7) implies that if $\gamma>1$, the budget deficit should be positive, and that the budget deficit equals the difference between the net savings of the younger generation consumers and the net savings of the older generation consumers. Note that in (7) $L_{f}$ and $\Pi_{2}$ are constant under full employment. Thus, (7) defines the budget deficit (or the government expenditure) which is necessary and sufficient to realize full employment under constant price given $T$. (7) is rewritten as

$$
(1-\alpha+\gamma \alpha)(G-T)=(\gamma-1)\left[(1-\alpha)\left(y L_{f}-G\right)-\alpha \Pi_{2} L_{f}\right]
$$

This defines the budget deficit (or the tax) which is necessary and sufficient to realize full employment under constant price given $G$.

Summarizing the results, we obtain 


\section{Macrothink}

Proposition 1 We need a budget deficit to achieve and maintain full employment under economic growth with constant price even if there are profit returns for the older generation consumers. The budget deficit equals the difference between the net savings of the younger generation consumers and that of the older generation consumers.

This budget deficit should not be offset by future surplus so long as the economy grows with constant price.

\section{Inflation by Excess Budget Deficit}

Let $\xi P_{2}=\frac{\xi}{1-\frac{1}{\eta}}$ be the price of the goods in Period 2, the nominal wage rate be $\xi \gamma y$, the government expenditure be $\zeta G$. Assume that excess budget deficit and inflation in Period 2 were not predicted by the older generation consumers in when they were young (in Period 1), and the younger generation consumers think that the price in Period 3 is the same as the price in Period $2^{2}$. The profit return for an older generation consumer is

$$
\Pi_{2}^{\prime}=\frac{1}{\eta-1} \gamma \xi y=\left(P_{2}-1\right) \gamma \xi y=\xi \Pi_{2} .
$$

We assume that the nominal value of the tax is $\gamma T$. The nominal total supply in Period 2 is

$$
\xi P_{2} \gamma y L_{f}
$$

Also, we assume that the profit return in the next period for a younger generation consumer is

$$
\Pi_{3}{ }^{\prime}=\gamma \Pi_{2}{ }^{\prime}
$$

The consumption of the older generation consumers is

$$
(1-\alpha)\left(y L_{f}+\Pi_{2} L_{f}-T\right)+(\xi-1) \Pi_{2} L_{f}
$$

Their net savings is

\footnotetext{
${ }^{2}$ If the older generation consumers had predicted inflation in Period 2 when they were young, this would have affected their consumption in Period 1, and complicated effects would have arisen, such as changing the size of the budget deficit at which full employment should be achieved at a given price, but it would not have changed the fact that an excessive budget deficit in Period 2 would have caused inflation.
} 


$$
\begin{gathered}
(1-\alpha)\left(y L_{f}+\Pi_{2} L_{f}-T\right)+(\xi-1) \Pi_{2} L_{f}-\Pi_{2} L_{f}-(\xi-1) \Pi_{2} L_{f} \\
=(1-\alpha)\left(y L_{f}-T\right)-\alpha \Pi_{2} L_{f} .
\end{gathered}
$$

The consumption of the younger generation consumers is

$$
\alpha \gamma\left(\xi y L_{f}+\xi \Pi_{2} L_{f}-T\right)
$$

Their net savings is

$$
(1-\alpha) \gamma\left(\xi y L_{f}+\xi \Pi_{2} L_{f}-T\right)-\gamma \xi \Pi_{2} L_{f}=(1-\alpha) \gamma\left(\xi y L_{f}-T\right)-\gamma \alpha \xi \Pi_{2} L_{f} .
$$

The nominal total demand is

$$
\alpha \gamma\left(\xi y L_{f}+\xi \Pi_{2} L_{f}-T\right)+(1-\alpha)\left(y L_{f}+\Pi_{2} L_{f}-T\right)+(\xi-1) \Pi_{2} L_{f}+\zeta G .
$$

From the equilibrium between the total supply and the total demand, we obtain

$$
\xi P_{2} \gamma y L_{f}=\alpha \gamma\left(\xi y L_{f}+\xi \Pi_{2} L_{f}-T\right)+(1-\alpha)\left(y L_{f}+\Pi_{2} L_{f}-T\right)+(\xi-1) \Pi_{2} L_{f}+\zeta G .
$$

From this

$$
\begin{gathered}
\xi \gamma y L_{f}=\alpha \gamma\left(\xi y L_{f}+\xi \Pi_{2} L_{f}-T\right)+(1-\alpha)\left(y L_{f}+\Pi_{2} L_{f}-T\right)+\zeta G \\
+(\xi-1) \Pi_{2} L_{f}-\xi \gamma\left(P_{2}-1\right) y L_{f} .
\end{gathered}
$$

Since $P_{2}=\frac{1}{1-\frac{1}{\eta}}$ and $\Pi_{2}=\left(P_{2}-1\right) \gamma y$, we get

$$
\begin{gathered}
\xi \gamma y L_{f}=\alpha \gamma\left(\xi y L_{f}+\xi \Pi_{2} L_{f}-T\right)+(1-\alpha)\left(y L_{f}+\Pi_{2} L_{f}-T\right) \\
+\zeta G+(\xi-1) \Pi_{2} L_{f}-\Pi_{2} L_{f} .
\end{gathered}
$$

Then,

$$
\begin{aligned}
& \zeta G-\gamma T=\gamma(1-\alpha)\left(\xi y L_{f}-T\right)-(1-\alpha)\left(y L_{f}-T\right) \\
& -(1-\alpha) \Pi_{2} L_{f}-\alpha \gamma \xi \Pi_{2} L_{f}+\Pi_{2} L_{f}
\end{aligned}
$$




$$
=\gamma\left[(1-\alpha)\left(\xi y L_{f}-T\right)-\alpha \xi \Pi_{2} L_{f}\right]-\left[(1-\alpha)\left(y L_{f}-T\right)-\alpha \Pi_{2} L_{f}\right] .
$$

This is the difference between the net savings of the younger generation consumers and that of the older generation consumers. Comparing this with (7),

$$
(\zeta G-\gamma T)-\gamma(G-T)=(1-\alpha)\left[\gamma\left(\xi y L_{f}-T\right)-\gamma\left(y L_{f}-T\right)\right]-\gamma \alpha \xi \Pi_{2} L_{f}+\gamma \alpha \Pi_{2} L_{f} .
$$

This is rewritten as

$$
(\zeta-\gamma) G=(\xi-1) \gamma\left[(1-\alpha) y L_{f}-\alpha \Pi_{2} L_{f}\right]
$$

When $(\zeta G-\gamma T)-\gamma(G-T)=(\zeta-\gamma) G>0$, we have $\xi>1$. This means inflation in Period 2. Summarizing the results in the following proposition,

Proposition 2 A budget deficit (given $\operatorname{tax}^{3}$ ) that exceeds the level necessary and sufficient to maintain full employment in a growing economy under constant price will cause inflation.

(8) means that even in this case the budget deficit equals the difference between the net savings of the younger generation consumers and that of the older generation consumers.

We need a stable budget deficit discussed in the previous section to prevent further inflation.

\section{Recession and Involuntary Unemployment by Insufficient Budget Deficit}

Let $L$ be the employment in Period 2. Assume that the government expenditure is $\zeta G$, the $\operatorname{tax}$ is $\gamma T$. The price of the goods is constant. The profit return for an older generation consumer is

$$
\Pi_{2}=\left(\frac{1}{\eta-1}\right) \gamma y \frac{L}{L_{f}}
$$

If full employment will be restored in Period 3, the profit return in the next period for a younger generation consumer is

$$
\Pi_{3}=\left(\frac{1}{\eta-1}\right) \gamma^{2} y
$$

\footnotetext{
${ }^{3}$ A change in fiscal spending and that in tax have different effects on the national income. An increase in fiscal spending and tax while keeping the budget deficit constant will lead to inflation, while a decrease in fiscal spending and tax while keeping the budget deficit constant will lead to a recession. It is because the multiplier of a change in tax is smaller than that of a change in fiscal spending. On the other hand, a change in tax influences on consumption of the older generation consumers in the next period.
} 


\section{Mll Macrothink}

The nominal total supply in Period 2 is

$$
\gamma P_{2} y L
$$

The consumption of the older generation consumers is

$$
(1-\alpha)\left(y L_{f}+\Pi_{2} L_{f}-T\right)
$$

Their net savings is

$$
(1-\alpha)\left(y L_{f}+\Pi_{2} L_{f}-T\right)-\Pi_{2} L_{f}=(1-\alpha)\left(y L_{f}-T\right)-\alpha \Pi_{2} L_{f} .
$$

The consumption of the younger generation consumers is

$$
\alpha\left(\gamma y L+\Pi_{3} L_{f}-\gamma T\right)
$$

Their net savings is

$$
(1-\alpha)\left(\gamma y L+\Pi_{3} L_{f}-\gamma T\right)-\gamma \Pi_{3} L_{f}=(1-\alpha)(\gamma y L-\gamma T)-\alpha \Pi_{3} L_{f} .
$$

The nominal total demand is

$$
\alpha\left(\gamma y L+\Pi_{3} L_{f}-\gamma T\right)+(1-\alpha)\left(y L_{f}+\Pi_{2} L_{f}-T\right)+\zeta G .
$$

From the equilibrium between the total supply and the total demand we obtain

$$
\gamma P_{2} y L=\alpha\left(\gamma y L+\Pi_{3} L_{f}-\gamma T\right)+(1-\alpha)\left(y L_{f}+\Pi_{2} L_{f}-T\right)+\zeta G,
$$

and then

$$
\begin{gathered}
\zeta G-\gamma T=\gamma(1-\alpha)(y L-T)-(1-\alpha)\left(y L_{f}-T\right)-\alpha \Pi_{3} L_{f}-(1-\alpha) \Pi_{2} L_{f} \\
+\left(P_{2}-1\right) \gamma y L .
\end{gathered}
$$

Since $P_{2}=\frac{1}{1-\frac{1}{\eta}}$ and $\Pi_{2}=\frac{\eta}{1-\eta} \gamma y \frac{L}{L_{f}}$, we get

$$
\zeta G-\gamma T=\left[\gamma(1-\alpha)(y L-T)-\alpha \Pi_{3} L_{f}\right]-\left[(1-\alpha)\left(y L_{f}-T\right)-\alpha \Pi_{2} L_{f}\right] .
$$

This is the difference between the net savings of the younger generation consumers and that of the older generation consumers. Assume that $\Pi_{3}$ in (9) equals $\gamma \Pi_{2}$ in (7). Comparing (9) 
with (7),

$$
\begin{aligned}
& (\zeta G-\gamma T)-\gamma(G-T)=\zeta G-\gamma G=(1-\alpha)\left[\gamma(y L-T)-\gamma\left(y L_{f}-T\right)\right] \\
& \quad=(1-\alpha) \gamma\left(L-L_{f}\right) .
\end{aligned}
$$

When $(\zeta G-\gamma T)-\gamma(G-T)=\zeta G-\gamma G<0, L<L_{f} \quad$ is derived. Then, there is involuntary unemployment ${ }^{4}$. Summarizing the results, we obtain

Proposition 3 A budget deficit (given $\operatorname{tax}^{5}$ ) that is insufficient to maintain full employment will cause a recession with involuntary unemployment.

(9) means that even in this case the budget deficit equals the difference between the net savings of the younger generation consumers and that of the older generation consumers. Note that in (9) the independent variables are $G$ and $T$. Therefore, the budget deficit (or the government expenditure and tax) determines the equilibrium values of the national income and the savings of consumers not that the savings of consumers determine the budget deficit.

\section{Recovery from Recession by the Government Expenditure}

We will recover full employment in Period 3. Suppose that the taxes in Periods 2 and 3 are $\gamma T$ and $\gamma^{2} T$. The price is constant at $P_{2}$. The total supply is

$$
\gamma^{2} P_{2} y L_{f}
$$

The profit return for an older generation consumer is denoted by

$$
\Pi_{3}=\left(\frac{1}{\eta-1}\right) \gamma^{2} y
$$

The profit return for a younger generation consumer is

$$
\Pi_{4}=\left(\frac{1}{\eta-1}\right) \gamma^{3} y=\gamma \Pi_{3}
$$

The consumption (or the savings) of the older generation consumers is

$$
(1-\alpha)\left[\gamma(y L-T)+\Pi_{3} L_{f}\right]
$$

Their net savings is

\footnotetext{
${ }^{4}$ About involuntary unemployment please see Hattori and Tanaka (2020).

${ }^{5}$ Please see footnote 2.
} 


$$
(1-\alpha)\left[\gamma(y L-T)+\Pi_{3} L_{f}\right]-\Pi_{3} L_{f}=(1-\alpha) \gamma(y L-T)-\alpha \Pi_{3} L_{f} .
$$

The consumption of the younger generation consumers is

$$
\alpha\left[\gamma^{2}\left(y L_{f}-T\right)+\gamma \Pi_{3} L_{f}\right]
$$

Their net savings is

$$
(1-\alpha)\left[\gamma^{2}\left(y L_{f}-T\right)+\gamma \Pi_{3} L_{f}\right]-\gamma \Pi_{3} L_{f}=(1-\alpha) \gamma^{2}\left(y L_{f}-T\right)-\alpha \gamma \Pi_{3} L_{f} .
$$

Let $\zeta G$ be the government expenditure. The total demand is

$$
\alpha\left[\gamma^{2}\left(y L_{f}-T\right)+\gamma \Pi_{3} L_{f}\right]+(1-\alpha)\left[\gamma(y L-T)+\Pi_{3} L_{f}\right]+\zeta G .
$$

Note that $L$ is employment in Period 2. From the equilibrium between the total supply and the total demand, we have

$$
\gamma^{2} P_{2} y L_{f}=\alpha\left[\gamma^{2}\left(y L_{f}-T\right)+\gamma \Pi_{3} L_{f}\right]+(1-\alpha)\left[\gamma(y L-T)+\Pi_{3} L_{f}\right]+\zeta G .
$$

On the other hand, if there is no recession, in Period 3 (6) means

$$
\gamma^{2} P_{2} y L_{f}=\alpha\left[\gamma^{2}\left(y L_{f}-T\right)+\gamma \Pi_{3} L_{f}\right]+(1-\alpha)\left[\gamma\left(y L_{f}-T\right)+\Pi_{3} L_{f}\right]+\gamma^{2} G .
$$

By (10) and (11),

$$
\zeta G-\gamma^{2} G=(1-\alpha) \gamma y\left(L_{f}-L\right)
$$

When $L<L_{f}$, we have $\zeta>\gamma^{2}$. Therefore, a larger budget deficit is required than would be required to maintain full employment in the absence of a recession. From (10) we obtain

$$
\begin{gathered}
\zeta G-\gamma^{2} T=(1-\alpha) \gamma^{2}\left(y L_{f}-T\right)-(1-\alpha) \gamma(y L-T)-\alpha \gamma \Pi_{3} L_{f} \\
-(1-\alpha) \Pi_{3} L_{f}+(p-1) \gamma^{2} y L_{f} .
\end{gathered}
$$

Since $P_{2}=\frac{1}{1-\frac{1}{\eta}} \quad$ and $\quad \Pi_{3}=\left(\frac{1}{\eta-1}\right) \gamma^{2} y$, this means

$$
\zeta G-\gamma^{2} T=(1-\alpha) \gamma^{2}\left(y L_{f}-T\right)-\alpha \gamma \Pi_{3} L_{f}-\left[(1-\alpha) \gamma(y L-T)-\alpha \Pi_{3} L_{f}\right] .
$$


Summarizing the results, we obtain

Proposition 4 A budget deficit larger than the one necessary and sufficient to maintain full employment without a recession can overcome a recession caused by insufficient budget deficit and restore full employment.

(12) means that even in this case the budget deficit equals the difference between the net savings of the younger generation consumers and that of the older generation consumers.

We should not offset the deficit created to overcome the recession by subsequent surpluses because we need a stable budget deficit to maintain full employment with economic growth under constant price.

\section{Recovery from Recession by the Tax Reduction}

Again, we will recover full employment in Period 3. The price is constant at $P_{2}$. Suppose that the government expenditures in Periods 2 and 3 are $\gamma G$ and $\gamma^{2} G$. As in the previous case the profit return for an older generation consumer is denoted by

$$
\Pi_{3}=\left(\frac{1}{\eta-1}\right) \gamma^{2} y
$$

The profit return for a younger generation consumer is

$$
\Pi_{4}=\left(\frac{1}{\eta-1}\right) \gamma^{3} y=\gamma \Pi_{3}
$$

The nominal total supply is

$$
\gamma^{2} P_{2} y L_{f}
$$

The consumption (or the savings) of the older generation consumers is

$$
(1-\alpha)\left(\gamma y L+\Pi_{3} L_{f}-\gamma T\right)
$$

Their net savings is

$$
(1-\alpha)\left(\gamma y L+\Pi_{3} L_{f}-\gamma T\right)-\Pi_{3} L_{f}=(1-\alpha)(\gamma y L-\gamma T)-\alpha \Pi_{3} L_{f}
$$

Let $\eta T$ be the tax in Period 3. Then, the consumption of the younger generation consumers is

$$
\alpha\left(\gamma^{2} y L_{f}+\gamma \Pi_{3} L_{f}-\eta T\right)
$$

Their net savings is

$$
(1-\alpha)\left(\gamma^{2} y L_{f}+\gamma \Pi_{3} L_{f}-\eta T\right)-\gamma \Pi_{3} L_{f}=(1-\alpha)\left(\gamma^{2} y L_{f}-\eta T\right)-\alpha \gamma \Pi_{3} L_{f} .
$$


The total demand is

$$
\alpha\left(\gamma^{2} y L_{f}+\gamma \Pi_{3} L_{f}-\eta T\right)+(1-\alpha)\left(\gamma y L+\Pi_{3} L_{f}-\gamma T\right)+\gamma^{2} G
$$

Note that $L$ is employment in Period 2. From the equilibrium between the total supply and the total demand, we have

$$
\gamma^{2} P_{2} y L_{f}=\alpha\left(\gamma^{2} y L_{f}+\gamma \Pi_{3} L_{f}-\eta T\right)+(1-\alpha)\left(\gamma y L+\Pi_{3} L_{f}-\gamma T\right)+\gamma^{2} G
$$

Again, if there is no recession, (11) holds in Period 3. By (11) and (13),

$$
\alpha\left(\gamma^{2}-\eta\right) T=(1-\alpha) \gamma y\left(L_{f}-L\right)
$$

When $L<L_{f}$, we get $\eta<\gamma^{2}$. Therefore, a larger budget deficit by tax reduction is required than would be required to maintain full employment in the absence of a recession. Since $\alpha<1$, we can see that the tax cut in this case must be larger than the additional fiscal spending in the previous case. This is because the marginal propensity to consume is smaller than one. However, as discussed in footnote 2, the tax cut will affect consumption in the next period and will have the same effect as an increase in fiscal spending in the long run.

From (13) we obtain

$$
\begin{gathered}
\gamma^{2} G-\eta T=(1-\alpha)\left(\gamma^{2} y L_{f}-\eta T\right)-(1-\alpha) \gamma(y L-T)-\alpha \gamma \Pi_{3} L_{f} \\
-(1-\alpha) \Pi_{3} L_{f}+\left(P_{2}-1\right) \gamma^{2} y L_{f}
\end{gathered}
$$

Since $\quad P_{2}=\frac{1}{1-\frac{1}{\eta}} \quad$ and $\quad \Pi_{3}=\left(\frac{1}{\eta-1}\right) \gamma^{2} y$, this means

$$
\gamma^{2} G-\eta T=(1-\alpha)\left(\gamma^{2} y L_{f}-\eta T\right)-\alpha \gamma \Pi_{3} L_{f}-\left[(1-\alpha) \gamma(y L-T)-\alpha \Pi_{3} L_{f}\right]
$$

Summarizing the results, we obtain

Proposition 5 A budget deficit larger than the one necessary and sufficient to maintain full employment without a recession can overcome a recession caused by insufficient budget deficit and restore full employment by tax reduction.

(15) means that even in this case the budget deficit equals the difference between the net savings of the younger generation consumers and that of the older generation consumers. 


\section{Concluding Remark}

Using a two-periods overlapping generations (OLG) model with production of goods in monopolistic competition with constant returns to scale technology and profit returns to older generation consumers, we have shown that excessive budget deficits lead to inflation, but budget deficits are necessary and useful for full employment under economic growth and overcoming recessions. Although in this paper we assume monopolistic competition to derive the existence of profits, similar conclusions may be drawn by considering an economy in which goods are produced by both capital and labor as factors of production. Assuming that the old generation consumers, who hold capital through savings, receive profits, the sum of which is included in aggregate supply because it is distributed from firm revenues along with wages paid to the younger generation. On the other hand, the older generation will probably allocate some of the profits to consumption in their youth in anticipation of receiving them. Or, by the same token, the younger generation will calculate the future profits they will receive and spend part of it on consumption in their younger years. The same conclusion holds because the net savings in youth will be less than the amount of consumption spent from the future profits received.

\section{Acknowledgment}

We thank the reviewers for their thorough reviews and highly appreciate the comments and suggestions, which significantly contributed to improving the quality of the publication. This work was supported by JSPS KAKENHI Grant Number 18K01594 in Japan.

\section{References}

Hattori, M., \& Tanaka, Y. (2020). Divisibility of labour supply and involuntary unemployment: a perfect competition model. Journal of Economics and Management, 16, 193-206. https://jem.fcu.edu.tw/assets/jem/past_issues/vol.16_no.2/PDF/vol.16_no.2_05.pdf

Kelton, S. (2020). The Deficit Myth: Modern Monetary Theory and the Birth of the People's Economy. Public Affairs.

Lerner, A. P. (1943). Functional finance and the federal debt. Social Research, 10, 38-51.

Lerner, A. P. (1944). The Economics of Control: Principles of Welfare Economics. Macmillan.

Mitchell, W., Wray, L. R., \& Watts, M. (2019). Macroeconomics. Red Globe Press.

Mochizuki, S. (2020). A book understanding MMT (in Japanese, MMT ga yokuwakaru hon). Shuwa System.

Morinaga, K. (2020). MMT will save Japan (in Japanese, MMT ga nihon wo sukuu). Takarajimasha.

Otaki, M. (2007). The dynamically extended Keynesian cross and the welfare-improving fiscal policy. Economics Letters, 96, 23-29. https://doi.org/10.1016/j.econlet.2006.12.005

Otaki, M. (2009). A welfare economics foundation for the full-employment policy. 


\section{Macrothink}

Journal of Social Science Studies

ISSN 2329-9150

2021, Vol. 8, No. 2

Economics Letters, 102, 1-3. https://doi.org/10.1016/j.econlet.2008.08.003

Otaki, M. (2015). Keynesian Economics and Price Theory: Re-orientation of a Theory of Monetary Economy. Springer. https://doi.org/10.1007/978-4-431-55345-8

Park, S. (2020). The fallacy of fiscal collapse (in Japanese, Zaisei hatanron no ayamari). Seitosha.

Wray, L. R. (2015). Modern Money Theory: A Primer on Macroeconomics for Sovereign Monetary Systems (2nd ed.). Palgrave Macmillan. 
Appendix: When the profit returns are received by the younger generation consumers

Suppose that the profit returns are received by the younger generation consumers. We consider a case of economic growth with full employment under constant price. Let $\Pi_{1}$ be the profit for a younger generation consumer in Period 1. Then,

$$
\Pi_{1}=\left(\frac{1}{\eta-1}\right) y
$$

The profit for a younger generation consumer in Period 2 is

$$
\Pi_{2}=\left(\frac{1}{\eta-1}\right) \gamma y=\gamma \Pi_{1}
$$

The savings of the younger generation consumers in Period 1 which is the consumption of the older generation consumers in Period 2 are

$$
(1-\alpha)\left(y L_{f}+\Pi_{1} L_{f}-T\right)
$$

The consumption of the younger generation consumers in Period 2 is

$$
\alpha\left(\gamma y L_{f}+\Pi_{2} L_{f}-\gamma T\right)=\alpha \gamma\left(y L_{f}+\Pi_{1} L_{f}-T\right) .
$$

The nominal total demand is

$$
\alpha \gamma\left(y L_{f}+\Pi_{1} L_{f}-T\right)+(1-\alpha)\left(y L_{f}+\Pi_{1} L_{f}-T\right)+\gamma G .
$$

From the equilibrium between the total supply and the total demand, we get

$$
\gamma p y L_{f}=\alpha \gamma\left(y L_{f}+\Pi_{1} L_{f}-T\right)+(1-\alpha)\left(y L_{f}+\Pi_{1} L_{f}-T\right)+\gamma G .
$$

Since $p=\frac{1}{1-\frac{1}{\eta}}$ and $\Pi_{1}=\left(\frac{1}{\eta-1}\right) y$, we obtain

$$
\gamma G-\gamma T=(1-\alpha) \gamma\left(y L_{f}+\Pi_{1} L_{f}-T\right)-(1-\alpha)\left(y L_{f}+\Pi_{1} L_{f}-T\right) .
$$


This means that if the profit returns are received by the younger generation consumers, the budget deficit equals the difference between the savings of the younger generation consumers and that of the older generation consumers in a case of economic growth with full employment under constant price. We can prove that this result holds in other cases, inflation case, recession case and so on, as well.

\section{Copyright Disclaimer}

Copyright for this article is retained by the author(s), with first publication rights granted to the journal.

This is an open-access article distributed under the terms and conditions of the Creative Commons Attribution license (http://creativecommons.org/licenses/by/4.0/). 